destruction of their hopes, and the next total solar eclipse will be as eagerly looked forward to as the one just hidden from them.

An interesting description of the scene in the neighbourhood of Vadsö appeared in Tuesday's Times, and the following is an abridgement of it.

On Sunday morning the Varanger Fiord in the north-east of Norway presented a scene which has probably never before been equalled in a latitude of $70^{\circ}$. The anchorage at the port of Vadsö was crowded with men-of-war, yachts, and passenger steamers, brought together by reason of the total solar eclipse. For several days the numerous astronomers on these ships have been engaged in landing their delicate and elaborate instruments, and transporting them to the beautiful sites which here abound.

By last night the laborious preparations of the different observing parties had been completed, and they awaited with what composure they might the momentous events of the morrow. In any circumstances an Arctic summer night, where broad daylight reigns throughout, is very different from a night in a temperate region. But on this occasion there were so many interruptions, partly by the arrival of friends in the various ships, that rest was but little thought of, and indeed from two to five and even earlier a succession of boats brought hundreds of passengers from the ships to the shore.

The fence which marked out the ground occupied by the observers was guarded by bluejackets, charged with the duty of keeping at a suitable distance the groups of picturesquely-clad Finns and Lapps, who gazed with astonishment on the strangers who had travelled so far, and on the wonderful appliances they had brought with them. Many of these Arctic inhabitants were, however, sufficiently sophisticated to be provided with the traditional pieces of smoked glass with which to make their own observations.

The sun could not be seen at the moment when the moon first made contact, though almost immediately afterwards it was visible with a slight encroachment on the brilliant edge, showing that the eclipse had commenced. For nearly an hour hope and fear then alternated. Everything, of course, depended on the condition of the sky at the moment of totality, and it was hoped that some of the characteristic phenomena of a total eclipse might be presented. This hope was strengthened as the crescent sun waned thinner and thinner and still remained visible.

As the supreme moment of totality approached, the broad landscape sensibly darkened, and the fiord became more gloomy. It was as if some mighty thunder-shower was about to descend; but, alas! the clouds again thickened, and the observation of the moment of actual totality, if effective at all, could only be made by glimpses with a telescope through a very dense medium. Some observers were, of course, constrained to limit their attention to their instruments, and to the sole discharge of the duties which had been entrusted to them. But many were in the position of being able to look at the sun until the crescent of light was about to disappear, and then face round to the opposite point of the horizon. The object of this manœuvre was to permit the observer to see the impressive spectacle of the advance of the lunar shadow over the earth.

The situation at Vadsö lent itself admirably to the observation of this magnificent phenomenon. As the shadow advanced across the fiord, it enveloped the training squadron as it lay at anchor, the details of the ships' rigging disappeared from view, and their lights gleamed forth brilliantly. Still the shadow pressed on with its majestic speed of a mile in every couple of seconds. It moved as swiftly as a cannon-ball until it reached the observers at Vadsö, and then announced to them in the most impressive manner that the supreme moment of their visit had arrived, and that totality was complete.

The darkness that then buried Vadsö and its numerous observers lasted for a minute and forty seconds. The unwonted spectacle hushed every one to silence. A few startled birds hurried past the camp, and amid the canopy of cloud which covered the heavens at least one observer descried a star. But, though all the visitors felt that the magnificent phenomena were worthy of being remembered as a life-long experience, yet it is none the less true that, from a scientific point of view, the result of all the labours at Vadsö was hardly anything.

The object of the astronomers, who erected at such vast pains great photographic instruments, was to depict the corona and to analyse with spectroscopes the light which it dispenses. It is true that during the time of totality they exposed their plates in accordance with the careful drill and organisation which were indispensable if full advantage was to be taken of the bries period. But, unfortunately, during the time of totality the clouds were obdurate, and nothing could be seen. The innumerable telescopes directed to the sun showed no more than the same instruments would have done if they remained still covered.

The Ioo seconds fled, marked only by the mechanical precision of the officer who counted them aloud. The astronomers might safely spare glances to the interesting view over land and sea. The light around them was not greater than that during a full moon, but in the distance mountain-tops could be descried which were not in the shadow and were shining brilliantly.

At last the darkness lifted, and the manner in which the light returned was almost startling in its suddenness. It was not that the sun became visible-this, indeed, did not at first happenbut when the moon had passed by, and when totality was over, the sun illumined the clouds, and this gave again the usual light of cloudy day when the orb itself is invisible. A few seconds later a glimpse was afforded of the crescent form of the sun, and then the clouds closed in once more, and did not withdraw until long after the moon had passed away from the disc.

\section{THE PHYSICAL LABORATORY AT LEIDEN} (HOLLAND).

WHEN a few years ago it appeared advisable to Prof Kamerlingh Onnes, the Director of the Physical Laboratory at the University of Leiden, to start the issue of a periodical paper which would contain a regular account of the research work that was going on in his laboratory, he decided upon the English language as being for various reasons the most suitable for the purpose. The "Communications from the Physical Laboratory at the University of Leiden" consist, as a rule, of more or less happy translations of contributions by Prof. Onnes and his pupils to the Proceedings of the "Koninklijke Akademie" of Amsterdam. They give short accounts of the researches that are carried out, and contain theoretical notes, as a rule, in direct connection with the experimental work. The full accounts of the investigations are mostly to be found elsewhere in various French, German or English periodicals. ${ }^{1}$ No. 23 of the series appeared lately, and the whole set, containing everything that has been done in the laboratory since I 885 , is now complete.

The most important characteristic which distinguishes the Leiden laboratory from most of its contemporaries is its installation for high-pressure and low temperature work. There are probably only one or two more places where an installation of this kind is permanently joined to a well-provided physical laboratory. Nos. 14 and 23 (especially the former) give a general idea of its gradual development and present arrangement.

Ever since I 883 Prof. Onnes has been working at this department. His object was in the first place to develop and improve the methods introduced by Cailletet, Pictet, Wroblewski, Olszewski, and to prepare larger quantities of liquid oxygen than before, so as to be able to decant it and use it as a cooling agent for experiments, especially on the liquefaction of hydrogen. The same object was, during the same years, striven after by Pictet, Olszewski and, in this country, by Dewar. Owing to want of sufficient funds and personal assistance, the work progressed very slowly, and it was not till June 1892 , that a small quantity of liquid oxygen was decanted, while in December 1893 half a litre was obtained. It is interesting to notice how entirely independent the Leiden work is from the others. In the first place, Prof. Onnes uses Pictet's cycle method, while Olszewski developed the method used by Wroblewski in conjunction with himself. Instead of sulphurous acid, used by Pictet, he introduced methylchloride in the first cycle (a suggestion of Cailletet's), while ethylene remained

I Archives Neerlandaises, Wiedemann's Annalen, Beiblatter, Zeitschrift für Physikalische Chemie, Philosophical Magazine. 
the second substance. Both substances are in continual circulation in metallic, self-contained cycles, which are worked by two Pictet conjugated pumps. While Olszewski introduced a steel cyclinder in which to liquefy oxygen, Prof. Onnes devised an "ethylene boiling flask" in which oxygen (or air) is condensed in a copper spiral. The glass apparatus into which the oxygen is poured is of original construction, and especially adapted for experimental work in oxygen (or air) baths of $\frac{1}{4}$ to $\frac{1}{2}$ litre.

Sometimes instead of the methylchloride cycle solid carbonic acid is used. Experiments on the insertion of a methane cycle between the ethylene and oxygen, with the ultimate object of condensing hydrogen, are still being carried on. Oxygen and air are taken from high-pressure cylinders, into which they are compressed either by a Brotherhood compressor (as used in launching torpedos) into a kind of model "cryogenic laboratory," as Prof. Onnes calls his creation, with emphasis on both cryogenic and laboratory. Occasional comparisons with other cryogenic installations illustrate this vividly. Dewar works with quantities of ethylene up to "a hundredweight" (40 kg.), while Prof. Onnes requires $1{ }^{\circ} 5 \mathrm{~kg}$., by aid of which $\frac{1}{4}$ to $\frac{1}{2}$ litre of oxygen is kept liquid. Pictet estimates the power required for experiments with liquid air at from 30 to 40 h.p., while in the Leiden laboratory only six or eight are required, even in exceptional cases. Olszewski gives his power as I-3 h.p., but it must not be forgotten that his system is not a continuous one, and that the largest quantity which his apparatus in its enlarged form yields is $200 \mathrm{cc}$., only $\frac{1}{3}$ of which gets into his boiling-glass. His experiments require a correspondingly smaller quantity of ethylene (I kg.).

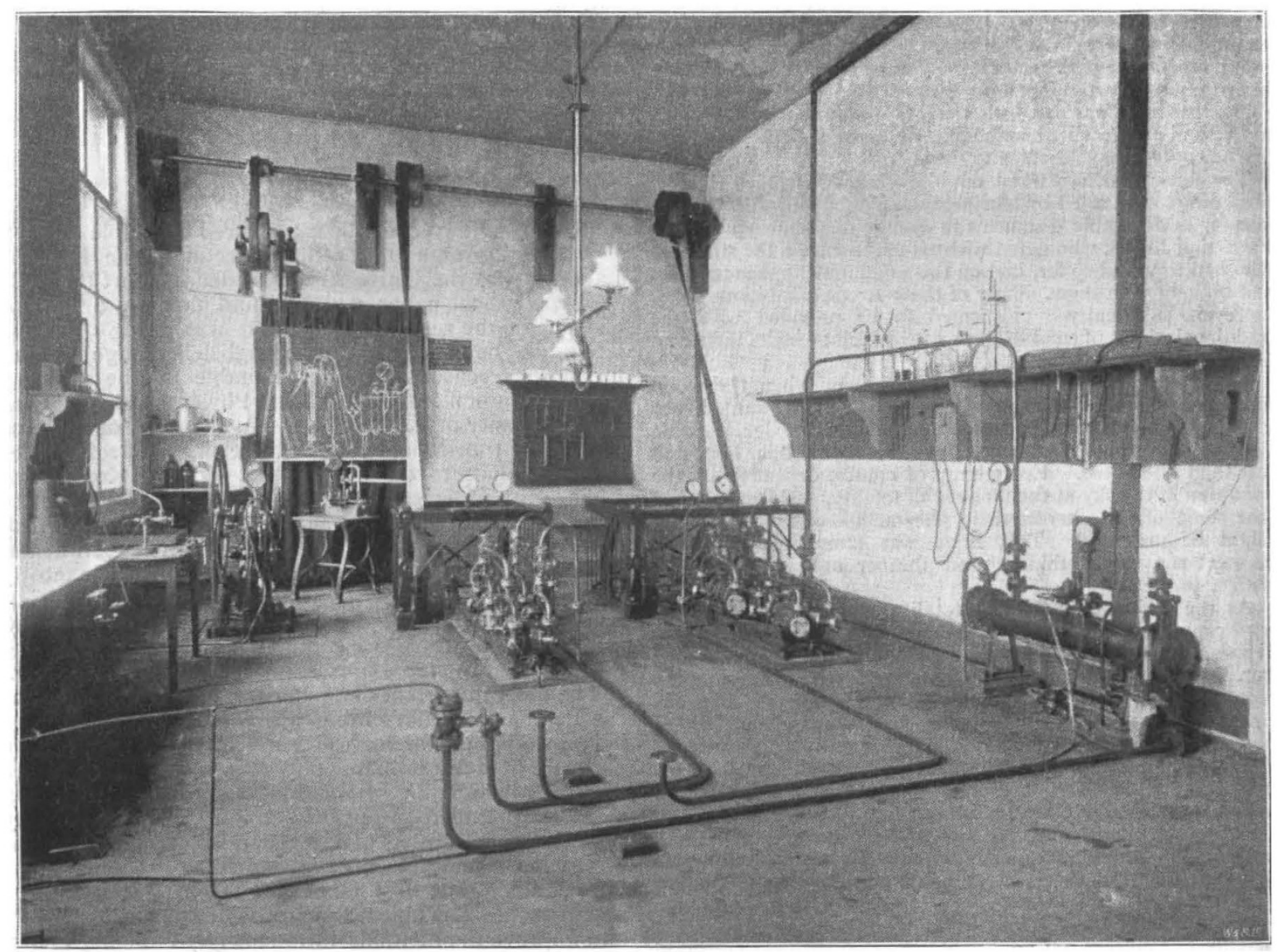

View of the cryogenic department in 1887 , showing the compressors destined for the chlormethyl, ethylene, and oxygen cycle. At the right the chlormethyl condenser.

or by a much less powerful, but in other respects highly superior Cailletet compressor. This compressor as modified, almost re-designed by Prof. Onnes, is a most desirable laboratory apparatus where high-pressure work with pure gases is being done. The chief modification is that the mercury column works in a steel U-tube, so that the piston with its lubricant (glycerine) is on one side above it, and the valves, \&c., on the other. This compressor may be fully depended upon; the gases remain just as pure as they were, and may be compressed to roo atmospheres without loss. (A full description of this compressor may shortly be expected.)

It is worth noticing that the greatest possible care is taken (and had to be taken) in the way of safety and of economy; these circumstances make the department NO. I 398 , VOL. 54 ]
It need hardly be said that these low figures have only been arrived at by a slow process of trial and gradual improvement, and one cannot but admire the perseverance and skill which the development of this system reveals.

Now that the cryogenic department is so far completed that baths of liquid oxygen and air may be readily prepared, no doubt the co-operation with the rest of the laboratory will become more regular and fruitful. Even now, in reading through the "Communications," we come repeatedly across instances in which the high-pressure and low temperature appliances have given invaluable help.

At one time, for instance, pure oxygen was required for experiments on the magnetic rotation in gases at high pressure (Nos. 7, I5). Commercial oxygen being too 
impure for the purpose, the preparation of a cubic metre of oxygen was undertaken. The gas was prepared by electrolysis, conducted through purifying apparatus, and compressed into a steel cyclinder of Io litres capacity, at a pressure of 100 atmospheres by the mercury compressor. The gas in the cylinder appeared to contain nearly 99 per cent. of oxygen. How many laboratories exist in which such a thing could be performed?

As to low temperatures, in No. 6 we notice the measurement of the capillary elevation of ether at $-\mathrm{IO}^{\circ}$ in boiling ethylene ; in No. I8, of the same magnitude for carbonic acid and nitrous oxide at $-24^{\circ}$ in boiling methylchloride. Nos. 4, 16, 18 contain the description of a method for purifying gases by condensation and fractional distillation at low temperature, in a bath of ethylene or in solid carbonic acid, the gases purified being carbonic acid, methylchloride, nitrous oxide, and ethane. Finally, we may note the measurement of the viscosity of methylchloride at $-30^{\circ}$ in cooled alcohol.

The different investigations hitherto carried out may be arranged under the following headings.

I. Cryogenic department : condensation of methane, isothermals of hydrogen at low temperatures, \&c. (Nos. I 4, 23.)

II. Investigations regarding critical points and condensation of mixtures and of pure substances. (Dr. Kuenen. Nos. 4, 7, 8, I I, I3, I6, I7.)

III. Measurements on the capillarity of ether, carbonic acid, nitrous oxide, \&c. (Drs. de Vries and Verschaffelt. Nos. 6, 18.)

IV. Measurements on the viscosity of methylchloride in connection with the laws of corresponding states of matter. (Drs. Stoel and de Haas. Nos. 2, I 2.)

V. Series of experiments on Kerr's magneto-optical phenomenon, \&c. (Drs. Sissingh, Wind and Zeeman. Nos. I, 3, 5, 8, 9, 10, I5, 20.)

VI. Some experiments regarding Hall's phenomenon in bismuth. (Dr. Lebret. Nos. 15 , 19.)

VII. On Hertz-waves in water and in electrolytes. (Dr. Zeeman, partly in conjunction with Prof. Cohn, Strassburg. Nos. 21, 22.)

VIII. Observations on the dispersion of magnetic rotation in gases. (Dr. Siertsema. Nos. 7, I 5.)

The scope of this article does not allow of a further description or discussion of any of the above investigations. One instance will show the scale on which the experiments are carried on, if deemed necessary. For the observations mentioned under VIII., two coils were constructed, each of $\mathrm{r}$ metre length and with 3600 turns of $6 \mathrm{~mm}$. wire, the joint resistance of the coils in series being I ohm, and the current carried 70 amperes.

Besides a dynamo there are two or three sets of accumulators, which make it possible to work simultaneously at two or three investigations for which strong currents and electric lamps are required. In short, the place is rich in apparatus of all kinds, and possesses numerous appliances; so much so, that one would rank it amongst the best provided (and, one may add, most productive) research laboratories. It is worth observing, that in Holland private munificence is hardly ever directed towards scientific work, and that the whole of this laboratory, as of all the others in the three Government Universities-Leiden, Utrecht, Groningen-are kept up from the public purse. It is only recently that, under the strain of the competition between the Universities, private societies have been founded to promote University work, where the Government shows itself unwilling or unable to provide the necessary means.

Those to whom these "Communications" are unknown, and who are desirous of becoming more intimately acquainted with their contents, have only to apply for copies to receive them. Prof. Onnes will, moreover, be very glad if physicists, touring in Holland, would alight at the famous University town, and in their programme include a visit to his laboratory.

$$
\text { NO. I 398, VOL. 54] }
$$

\section{THE GREAT RIFT VALLEY ${ }^{1}$}

$\mathrm{T}$ is but rarely that a narrative of travel, however interesting it may be, and however exciting the adventures of the author may have proved, has as much attraction for naturalists and geologists as the present volume possesses. Dr. Gregory has shown himself a thoroughly competent explorer, for he succeeded in reaching the glaciers close to the summit of Mount Kenya, the highest peak of British East Africa, a task in which several previous travellers had failed; and he also examined a considerable length of the extraordinary tract that gives its name to the book before us. This, too, was accomplished with a much smaller caravan than was regarded by experienced men as necessary for safety; in face of difficulties, due to the proclivities of the natives. and to scarcity of food, that would have daunted many men; in spite of the utter failure of the expedition to which the author was originally attached; and, above all, clespite severe attacks of malarial fever and dysentery. "The Great Rift Valley," apart from its scientific interest, gives a very interesting account of an adventurous exploit, carried out with courage and firmncss, and, at the same time, with kindly treatment of the natives employed and encountered.

It is, however, not as a record of exploration alone that this book needs notice. Explorers equal to 1$) \mathrm{r}$. Gregory in courage and tact, and perhaps superior to him in the power of resisting malarial influences, have made their way through many of the forests and deserts of Africa, and have told some of the secrets of the Dark Continent to an appreciative audience; but very few of those who returned to tell the tale of their adventures possessed the scientific training that gives an especial value to Dr. Gregory's account of his travels. In this respect the author of the present work is singularly qualified. In the era of specialisation in science that we have now entered upon, it is becoming rare to find a geologist who knows anything of zoology or botany, or a zoologist or botanist who can tell schist from shale or sandstone from granite; whilst it appears to be rapidly becoming a point almost of honour with the geologists, zoologists, and botanists of the British Islands to regard palæontology as an inferior science. It is therefore noteworthy that Dr. Gregory, who is a palaeontologist, should have brought back from Eastern Africa a mass of observations that could not have been accumulated by a geologist ignorant of biology, nor by a zoologist or botanist unacquainted with geology.

Briefly the history of the journey described is this. In November I892, Dr. Gregory received leave of absence from the Trustees of the British Museum to enable him to join an expedition to Lake Rudolf. From various causes this expedition was a failure. After the dispersal of its members, Dr. Gregory went on to Mombasa, where he engaged a small party of porters, and in March 1893 started for Lake Baringo and. Mount Kenya, and succeeded in reaching both. The journey occupied five months, and the expedition returned to Mombasa in August.

The arrangement of the present work is the following. After an introduction, giving a general account of previous exploration, and of the geology of the area as known before the author's visit, the first three chapters relate his experience with the abortive expedition which started from Lamu to explore Lake Rudolf and the regions between that lake and the Red Sea, but never got beyond the lower reaches of the Tana River; then eight chapters contain a description of the journey to Baringo and Kenya ; and the third part of the book, comprising

1 "The Great Rift Valley: being the Narrative of a Journey to Mount Kenya and Lake Baringo, with some Account of the Geology, Natural History, Anthropology, and Future Prospects of British East Africa." By (Natural History). (London: John Murray, 1896.) 